\title{
Vaginal microbiome and sexually transmitted infections: an epidemiologic perspective
}

\author{
Rebecca M. Brotman
}

Department of Epidemiology and Public Health and the Institute for Genome Sciences, University of Maryland School of Medicine, Baltimore, Maryland, USA.

\begin{abstract}
Vaginal bacterial communities are thought to help prevent sexually transmitted infections. Bacterial vaginosis (BV) is a common clinical syndrome in which the protective lactic acid-producing bacteria (mainly species of the Lactobacillus genus) are supplanted by a diverse array of anaerobic bacteria. Epidemiologically, BV has been shown to be an independent risk factor for adverse outcomes including preterm birth, development of pelvic inflammatory disease, and acquisition of sexually transmitted infections. Longitudinal studies of the vaginal microbiome using molecular techniques such as $16 \mathrm{~S}$ ribosomal DNA analysis may lead to interventions that shift the vaginal microbiota toward more protective states.
\end{abstract}

\section{Introduction}

Bacterial vaginosis (BV) is a gynecologic condition of unknown etiology and is traditionally characterized by a relatively low abundance of vaginal Lactobacillus sp. accompanied by polymicrobial anaerobic overgrowth (1). BV is the cause of considerable morbidity and is the most cited cause of vaginal symptoms prompting women to seek primary health care (2). Epidemiologic studies have demonstrated that BV is associated with a markedly increased risk for acquisition of sexually transmitted infections (STIs) (3-6), including HIV (5, 7-10), and the development of pelvic inflammatory disease (PID) (11). Transmission of STIs is also associated with BV, since BV increases viral replication and vaginal shedding of HIV-1 $(7,12-14)$ and herpes simplex virus type 2 (HSV-2) (15). During pregnancy, BV has been linked to late fetal loss, and $10 \%-30 \%$ of pregnant women with $\mathrm{BV}$ give birth prematurely, although there is a lack of consistent evidence that treatment of BV reduces the risk of preterm delivery (16-23). Further complicating research and clinical practice is the fact that women with BV are only slightly more likely than women without BV to report vaginal symptoms (24). Thus, BV may be a relatively nonspecific marker of risk, motivating the development of new biomarkers for investigating and managing the vaginal microbiome.

The focus of this Review is the epidemiologic evidence that the vaginal microbiome in a "low-lactobacillus" state, for lack of a better term and as observed in the clinical syndrome BV, is a biological risk factor for both the acquisition and transmission of STIs. To approach this topic, the diagnosis and classification of BV requires in-depth discussion, encompassing the bacterial diversity of the vagina and the role of lactobacilli and other lactic acid-producing bacteria, the epidemiology of $\mathrm{BV}$, and a review of the vaginal microbiome's ability to help prevent STIs.

\section{Epidemiology of BV}

Cultivation-based studies traditionally identify BV as associated with a shift in the relative abundance of various species of Lactobacillus to greater abundance of strictly anaerobic bacteria, including Gardnerella vaginalis, Prevotella spp., Mobiluncus spp., Ureaplasma urealyticum, and Mycoplasma hominis (1). However,

Conflict of interest: The author has declared that no conflict of interest exists. Citation for this article: J Clin Invest. 2011;121(12):4610-4617. doi:10.1172/JCI57172. the majority of bacterial species (>99\%) have not been cultivated in the laboratory (25). Molecular approaches now enable their identification. In the past several years, investigators have more regularly used 16 S rRNA gene sequence-based analysis $(26,27)$ to survey the vaginal microbiota (28-30). These studies have found a multitude of bacteria that could not be identified by traditional culture-based methods. Recently, molecular studies have shown that Atopobium vaginae, Megasphaera, members of the candidate division TM7, Eggerthella-like uncultured bacteria, and three newly described members of the Clostridiales order have high specificity for $\mathrm{BV}(28,29)$. These bacteria represent the great diversity of microbes that are present in microbiota of women with BV, but it is not yet known whether these microorganisms are single pathogens that cause $\mathrm{BV}$ or whether $\mathrm{BV}$ is caused by complex communities of bacteria. Interventions to treat $\mathrm{BV}$ focus on the use of antibiotics, but the effectiveness of such treatments is disappointingly low, and recurrence is common $(31,32)$, indicating that we do not yet have an adequate understanding of the pathology involved (33).

The diagnosis of BV (34) is based on clinical criteria or Gram stain, which are both fairly subjective and thus complicate research and clinical practice. Direct Gram stain of vaginal secretions, such as those that use the Nugent or Ison/Hay scoring systems (35-37), have been used for the past 25 years, and this technique evaluates the morphology and Gram stain reactivity of bacteria. The scoring method described by Nugent et al. (37) reflects the relative abundance of large Gram-positive rods (i.e., lactobacilli), Gram-negative and Gram-variable rods and cocci (i.e., G. vaginalis, Prevotella, Porphyromonas, and peptostreptococci), and curved Gram-negative rods (Mobiluncus). The technique allows rough assessment of relative abundance of bacteria, allowing for classification of bacterial load, as well as the number of polymorphonuclear (PMN) cells, candidal spores, fungal hyphae, and sperm. It is based on a linear scale ranging from $0-10$; a score of $0-3$ is considered healthy, $4-6$ as intermediate, and $7-10$ as indicative of BV. While Gram staining is a common method of assessing BV in research studies, the scoring of specimens can be variant among reviewers (38). Gram-stained vaginal smears also require skilled personnel to perform the scoring and are not used in usual clinical practice. Nonetheless, with a sensitivity of $89 \%$ and specificity of $83 \%$ (39) compared with Amsel clinical criteria (described below), the Nugent Gram stain test 
remains a commonly used tool (40), and it can be performed with self-collected vaginal smears (41), facilitating longitudinal field-based studies $(42,43)$.

In clinical settings, $\mathrm{BV}$ is diagnosed by the presence of three of the following criteria described by Amsel et al.: elevated vaginal $\mathrm{pH}$ of more than 4.5; thin, homogeneous gray-white discharge; amine odor upon the addition of $10 \%$ potassium hydroxide $(\mathrm{KOH})$ to vaginal fluid on a glass slide; and the presence of "clue cells" (vaginal epithelial cells with indistinct borders due to attached bacteria) on microscopic examination of vaginal fluid (2). The sensitivity and specificity of the Amsel criteria is $70 \%$ and $94 \%$, respectively, when compared with Nugent Gram stain scores (39).

$\mathrm{BV}$ is not a reportable condition, and therefore, estimates of prevalence vary according to the population studied. Prevalence of BV based on Amsel criteria ranges between 24\% and 30\% in sexually transmitted disease (STD) clinic populations (44-46), and based on Gram-stained smears, estimates have ranged from 9\% (47) to $18 \%$ (48) in United Kingdom (UK) clinic-based studies, and have been reported as $29 \%$ in a US population-based survey (40) and over $50 \%$ in rural Ugandan villages (49). A comparison of Gram stain versus clinical criteria reveals that both are effective for the diagnosis of symptomatic BV; however, the Amsel criteria do not convey information on the composition of vaginal microbiota, and the Gram stain provides only morphological information, which provides limited insight into the composition of the vaginal microbiota. For example, in a study using molecular methods, Fredricks et al. pointed out in 2005 that Mobiluncus morphotypes on Gram stain may reflect the detection of BVAB1 (a bacteria from the Clostridiales order) (28). While a high Nugent score slide is visually quite distinct from a low Nugent score slide, intermediate smears are more difficult to read and specific errors in classifying morphotype on Gram stain are likely. The Ison/Hay Gram stain criteria approach the difficult problem of scoring the intermediate state (50). A molecular diagnostic tool that combines aspects of symptomatology, host response, and vaginal microbial communities would certainly provide refinement for the diagnosis of BV and add an unbiased means for detecting changes in the vaginal ecosystem that put women at risk for reproductive health sequelae $(51,52)$.

Numerous epidemiologic investigations have been done to identify factors that increase a woman's risk of BV. The concordance of BV status in monogamous lesbian couples ranges up to $95 \%(53,54)$, strongly suggesting that BV is sexually associated, although an infectious correlate has not been identified (55). Menses, a new sexual partner, vaginal douching, receptive oral sex, and lack of condom use are among the strongest risk factors for $\mathrm{BV}(54,56-63)$. In general, women with BV have more sex partners and an earlier age of sexual debut than women without BV (62). Results of studies on the treatment of male sexual partners to reduce BV incidence and recurrence have been mixed (64-67), which may be due to methodological issues, antibiotic dosing protocols, and limited sample size.

Despite over a century of work (68), we do not fully understand how protective vaginal microbiota are maintained, why frequent shifts in microbial composition occur, or how these shifts induce changes in the vaginal environment that relate to the dramatic increase in susceptibility to such a wide range of adverse health outcomes. These questions highlight the need for longitudinal sampling of a large number of women to significantly advance our understanding of the microbiological, biochemical, molecular, and behavioral contributions to the etiology of BV.

\section{Bacterial diversity of the human vagina}

Molecular studies have shown that bacterial communities of the human vagina vary in species composition $(28,30,69)$, and therefore it is likely that they respond differently in the context of pathologic reproductive tract disease or extrinsic disturbances during menstruation, sexual activity, or feminine hygiene practices, among other events. In a recent study by Ravel et al. of 396 asymptomatic US women equally representing four ethnic/racial groups, 282 bacterial phylotypes were observed in the mid-vagina by pyrosequencing of barcoded $16 \mathrm{~S}$ rRNA genes (30). In $73 \%$ percent of the participants, this pyrosequencing demonstrated that the vaginal microbiome was dominated (>50\% abundance) by one or more species of Lactobacillus (Figure 1). From the 282 phylotypes, Ravel et al. found the vaginal microbiota clustered into five groups of bacterial communities; four were dominated by Lactobacillus species (L. iners, L. crispatus, L. gasseri, L. jensenii), but one lacked significant numbers of lactobacilli, accounting for $27 \%$ of women. The latter group (termed group IV community state type) was characterized by a greater and more equally represented abundance of strictly anaerobic organisms, including members of the genera Atopobium, Corynebacterium, Anaerococcus, Peptonipbilus, Prevotella, and Finegoldia.

It was not a surprise that four of the five community state types described by Ravel et al. (30) were dominated by lactobacillus. Lactobacilli have long been considered to be a dominant and a protective vaginal bacterium, although the specific mechanisms by which the vaginal ecosystem restricts the growth of nonindigenous organisms are unknown. It is hypothesized that lactobacilli benefit the vagina by producing lactic acid as a fermentation product that accumulates in the environment and lowers the $\mathrm{pH}$ to a protective level of 4.5 or lower (70). Lactobacilli also produce bacteriocins, low-molecular weight proteins that can inhibit the growth of a variety of bacteria including G. vaginalis, reinforcing the protective role of the lactobacilli (71-73). In addition, sialidases and prolidases, proteases produced by BV-associated bacteria, affect vaginal mucosal cell exfoliation and degradation of mucus glycoproteins, which are thought to be major components of the barrier against infection (74).

Interestingly, at any given time point, the Ravel et al. data suggest that approximately one-fourth of asymptomatic reproductive-age women lack a lactobacillus-dominated microbiota and almost half have a $\mathrm{pH}$ greater than 4.5 (30). As mentioned above, increased $\mathrm{pH}$ (>4.5) is one of the diagnostic features of BV (2). Lactic acid appears to be the primary vaginal acidifier; when lactobacilli predominate, vaginal secretions have been thought to have a $\mathrm{pH}$ of less than 4.2 and a lactic acid concentration of approximately $0.2 \%$ (75). Furthermore, O'Hanlon et al. presented compelling evidence suggesting that if measurements of vaginal secretions are made under hypoxic conditions that mimic the vagina, $\mathrm{pH}$ is lower and lactic acid concentrations are higher than in data previously reported under aerobic conditions (76). Lactic acid may also prove to be more effective than acidity alone in preventing overgrowth of bacteria and acquisition of sexually transmitted organisms $(77,78)$. Under aerobic conditions, some lactobacilli can produce hydrogen peroxide (another inhibitor of anaerobes and other organisms), but little if any hydrogen peroxide is detectable in vaginal secretions due to the hypoxic environment and the high antioxidant capacity of vaginal secretions $(78,79)$.

The malodorous discharge associated with BV results from the presence of volatile amines (particularly trimethylamine) (80) thought to be metabolic by-products of anaerobic bacteria. 
A

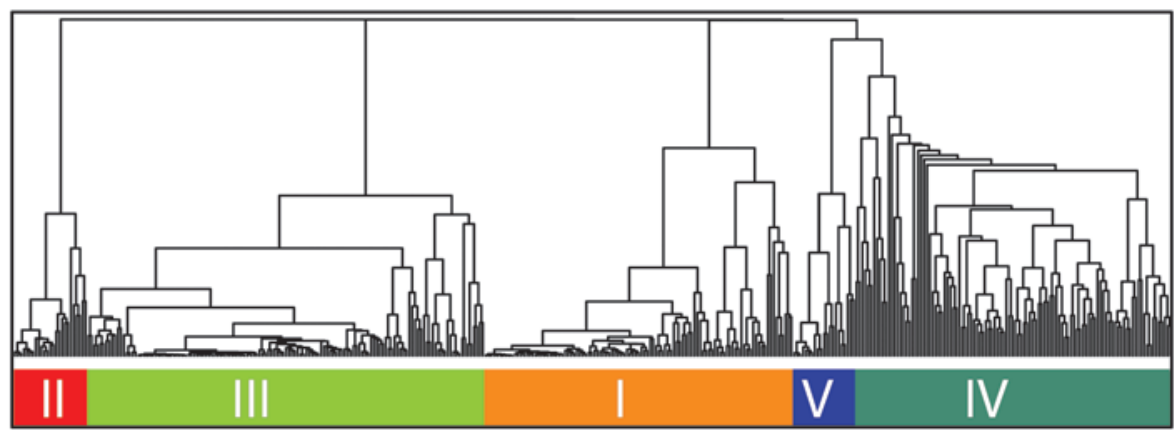

Community groups

B

$\mathrm{pH}$

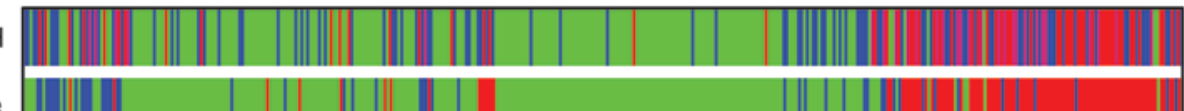

Nugent score

L. iners

L. crispatus

L. gasseri

L. jensenii

Prevotella

Megasphaera

Sneathia

Atopobium

Streptococcus

Dialister

Lachnospira

Anaerococcus

Peptoniphilus

Eggerthella

Finegoldia

Rhodobaca

Anaerotruncus

Ureaplasma

Mycoplasma

Aerococcus

Parvimonas

Staphylococcus

Corynebacterium

Veillonella

L. vaginalis

C

Community groups

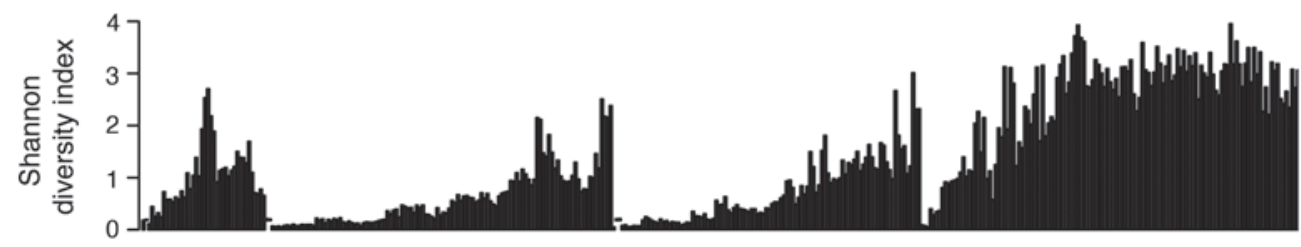




\section{Figure 1}

Heat map showing the distribution of microbial taxa found in the vaginal microbial communities of 394 reproductive-age women. (A) Complete linkage clustering of samples based on species composition and abundance in communities. (B) Nugent scores and $\mathrm{pH}$ measurements for each of the 394 samples. (C) Shannon diversity indices calculated for each of the 394 vaginal communities (two singletons were excluded). Adapted with permission from Proceedings of the National Academy of Sciences of the United States of America (30).

The amines are also associated with increased vaginal transudation and squamous epithelial cell exfoliation, which lead to the vaginal discharge seen in the BV patient. As mentioned above, a noteworthy finding from the work of Ravel et al. was that Lactobacillus sp. were not the dominant species in $27 \%$ of the women who were surveyed (30). This was an intriguing result because the participants did not report any vaginal symptoms (including malodor and discharge) on direct questioning despite having a microbial community that was similar in composition to that of women diagnosed with clinically defined $\mathrm{BV}(28,81)$. Interestingly, Klebanoff et al. demonstrated in a larger study of 2,888 women that as many as $50 \%$ of women with high Nugent scores (indicative of BV) are asymptomatic (24). Of course, the limitations of self reporting vaginal symptoms are that responses may be subject to reporting biases (82) or poor recognition of symptoms. The term $B V$, based on Amsel criteria or Nugent scores, does not necessarily distinguish a woman's self-reported symptomatic or asymptomatic states, adding another layer of complexity in research studies seeking to lead to an understanding of the risk factors associated with a given health outcome. The factors leading to and the adverse outcomes resulting from symptomatic BV and asymptomatic BV are not fully understood and are an active area of research.

In addition, Ravel et al. found that women presenting in the low-lactobacillus community state type tended to have higher Nugent scores, and Atopobium sp., another lactic acid-producing bacteria, was often found in relatively high proportions (30). The standard that women with healthy vaginal communities are always colonized with high numbers of lactobacilli has been disputed by Forney et al. (83). This group asserted that communities that lack Lactobacillus sp. may have high numbers of other lactic acid-producing bacteria, such as Atopobium spp., Megasphaera spp., or Leptotrichia spp., which may serve the same ecologic function for maintaining lactic acid and acidity in the vagina. So, while it is well established that BV-positive women lack significant numbers of Lactobacillus sp., $(28,81)$, questions arise: are all women in the low-lactobacillus state, with relatively diverse microbiota, at risk for reproductive tract sequelae? Or are there other factors, specific communities of bacteria or host responses that elevate risk? Epidemiologic studies have clearly shown that both clinically defined BV and high Nugent scores, regardless of vaginal symptoms, are associated with adverse health outcomes in women. However, BV remains a very broad category that includes a substantial spectrum of host responses and vaginal microbial communities. Estimates derived from such epidemiologic studies may suffer from residual confounding because women are categorized together based on Gram stain or symptomatology, and additional biological information would further refine the estimates reported in these studies. Research is further complicated by the rapid fluctuation of vaginal microbiota discussed in the next section.

\section{Dynamics of the vaginal microbiota: another layer of complexity}

Understanding the dynamics of the vaginal ecosystem would refine our knowledge of the factors associated with increased risk of adverse outcomes. Studies using molecular tools, microscopy, and culture-based methods have documented frequent and rapid fluctuations in the composition of vaginal communities (61, 63, 84-87). Verstraelen et al. reported on vaginal microbiota of pregnant women at two time points: 9 and 32 gestational weeks (88). They concluded that $L$. crispatus promotes the stability of normal microbiota, while $L$. gasseri and/or $L$. iners are associated with the occurrence of abnormal microbiota based on Gram-stained smears. Srinivasan et al. reported on 22 women assessed daily for 7 or 14 days and then at 2,3 , and 4 weeks using a panel of 11 bacterium-specific quantitative PCR (qPCR) assays (89). They concluded that the microbiota of the human vagina can be highly dynamic and that women without BV were colonized with Lactobacillus sp., but that levels changed dramatically over the course of a month. G. vaginalis also increased in abundance during menses. However, these genomic studies have not yet incorporated time-varying behavioral and epidemiologic information or evaluated healthy nonpregnant women. Such data are forthcoming from the NIH Human Microbiome Project $(90,91)$.

In a 16-week observational study of reproductive-age women with twice-weekly Nugent Gram stain scoring of vaginal smears (42), our group found that menses in the 10 days prior to vaginal sampling, vaginal lubricant use reported the day prior, and rectal sex within two days prior were associated with incidence of high Nugent score when compared with a woman's own intervals of persistently low Nugent score (ref. 61 and Figure 2), highlighting the fluctuation in Nugent scores observed among four of the 33 women studied over 16 weeks of observation. Nine women (27\%) were observed to have persistently low Nugent scores, while the Nugent scores of 16 women (48\%) fluctuated (61). The duration of high Nugent scoring varied widely, but often (51\% of the time) it lasted less than the sampling interval of three days. Among women who had a high Nugent score episode, the mean number of episodes observed was 8.7, for an average of approximately two high scores per month. These Gram stain studies are certainly suggestive, and several groups, including ours, have ongoing genomic studies which are investigating why the vaginal microbiota fluctuate and the outcomes associated with such fluctuations. Menstrual bleeding, the hormonal fluctuation over the menstrual cycle, sexual behaviors, hygiene practices, new sexual partners, diet, and vaginal bacterial community composition are known to be contributors to fluctuation of vaginal bacterial communities based on microscopy and cultivation-based studies (63, 92-94); genomic studies will benefit the investigation of how these behavioral and extrinsic factors affect bacterial composition and abundance.

We conclude from these longitudinal studies that the vaginal microbiota fluctuate rapidly and that the intervals of fluctuation, or the increased frequency and duration of fluctuations, may provide discrete episodes of increased risk (61). In addition, longitudinal studies reveal a weakness in the use of cross-sectional study designs: dramatic fluctuations in abundance and composition of bacterial communities are missed if samples are infrequently collected. Future studies must use longitudinal designs in which large numbers of women are frequently sampled and time-varying data on menses and behaviors are collected rigorously, so changes in vaginal community composition and their association with adverse health outcomes can be fully gauged. 

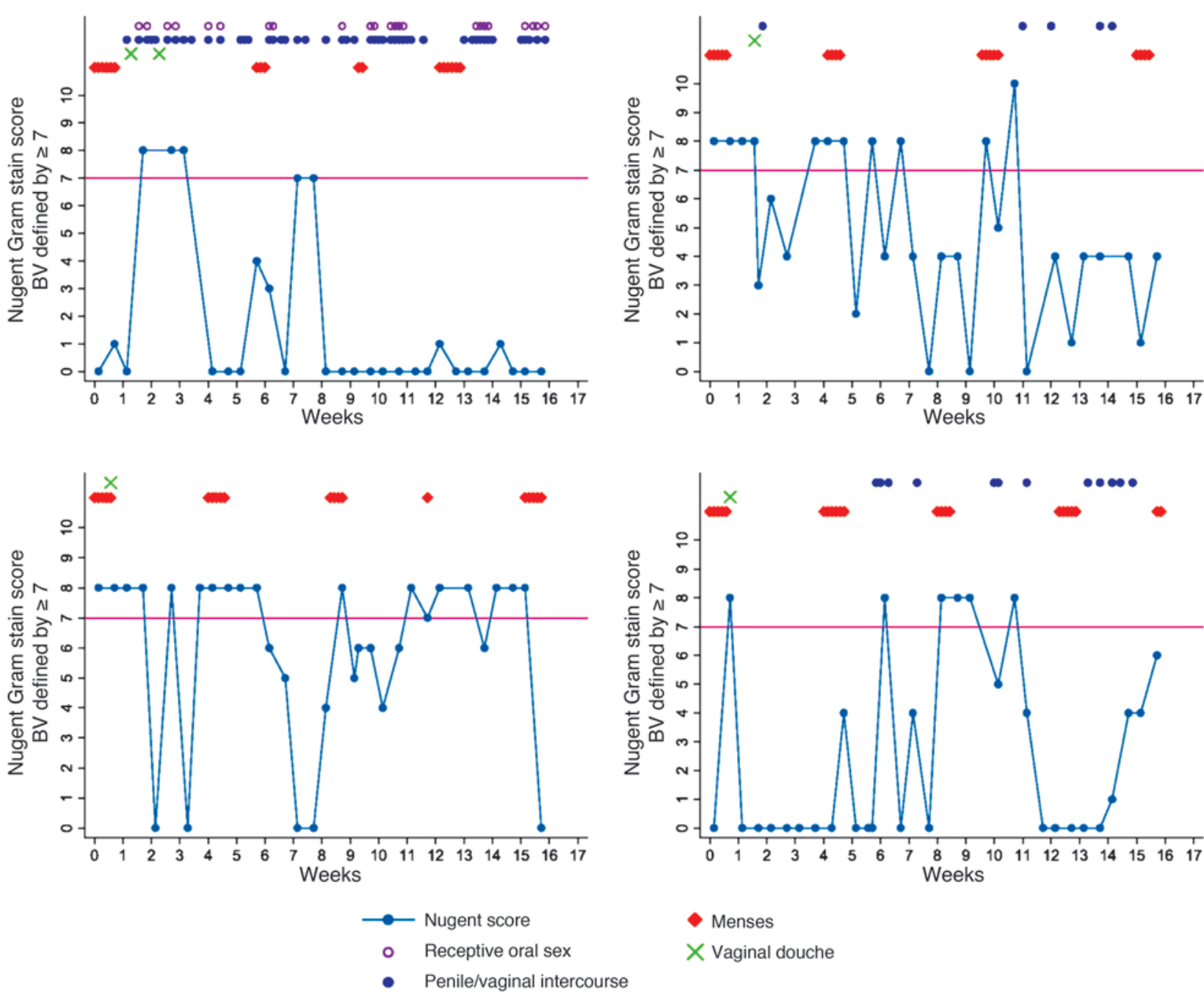

Figure 2

Rapid fluctuation of Nugent Gram stain score in 4 women who self collected vaginal swabs twice weekly for 16 weeks. Adapted with permission from Sexually Transmitted Infections (61).

Field-based longitudinal studies require self sampling

The studies described below, which find an association between vaginal microbiota and STIs, relied on vaginal specimens from the mid-vagina. Self-collected vaginal swabs of the mid-vagina are the only realistic and economical method to use for sampling in large, field-based, longitudinal studies. Asking participants to be examined by a clinician (weekly or more often) is expensive, not feasible, and results in loss to follow-up in large epidemiologic studies. Women also report greater comfort with self-collected vaginal specimens instead of clinician-collected specimens (95).

Given the need for self sampling, at question then is reliability of the data. In 2009, Kim et al. published a culture-independent study of physician-collected swabs that reported heterogeneity in microbial population across the cervix, fornix, and outer vaginal canal within a woman (96). Kim et al. also reported heterogeneity by sampling method used (scraping vs. swabbing). There were some concerns that the differences found during swabbing versus scraping were due to sampling method or perturbations during sampling. In contrast, there are several studies that suggest little differences in community composition of the mid-vagina (97-99). In a well-designed and statistically rigorous study, Forney et al. reported in 2010 that vaginal microbial community comparative statistical analyses of both T-RFLP and 16S rRNA gene sequence data sets revealed that self-collected vaginal swabs sampled the same microbial diversity as physician-collected swabs of the midvagina (98). Using qPCR assays of BV-associated bacteria, Menard et al. also found a high level of agreement between self-collected and practitioner-collected vaginal swabs (99). Nelson et al. demonstrated that self-collected vaginal swabs demonstrate high overall and morphotype-specific validity compared with provider-collected swabs, based on Gram stain evaluation using the Nugent criteria (97). We would expect that if there were major differences in the vaginal community composition by anatomical site, we would see differences in physician-collected versus self-collected swabs.

\section{Vaginal microbiota and risk for STIs}

Both ulcerative (syphilis, chancroid, and herpes) and nonulcerative (gonorrhea and chlamydia) STIs have been associated with 
higher rates of transmission and acquisition of HIV (100-102). Numerous longitudinal studies have also demonstrated that $\mathrm{BV}$-associated vaginal microbiota (defined by low-lactobacillus states upon cultivation, Gram stain of mid-vaginal smears, or clinical criteria for $\mathrm{BV}$ ) are associated with increased incidence of STIs $(5,6,103,104)$.

In the largest longitudinal cohort study ( $n=3,620$ women followed quarterly for one year) to evaluate vaginal microbiota as a risk factor for incidence of STIs, the NIH Longitudinal Study of Vaginal Flora (LSVF) study team found that intermediate and high Nugent scores were associated with a 1.5 - to 2 -fold increased risk for incident trichomonal, gonococcal, and/or chlamydial infection (104). A limitation to the study was that assessment for vaginal microbiota occurred three months prior to the detection of the incident STI. A more rigorously designed study would require daily or weekly vaginal sampling over an extended time frame (1 year) and in a large enough cohort of women to capture a sufficient number of incident STI cases for study. Such an intensive study design would also consume substantial funding resources. While the hazard ratio reported by the LSVF was in the 1.5 - to 2 -fold range, it is a crude estimate that is still suggestive that on the population level, women with high Gram stain scores are at increased risk for STIs. In addition, a woman who presents with a high Nugent score or a given vaginal microbiota at a single visit will likely maintain or return to the same state on any given day during the following interval when STI exposure occurs (105). In the worst epidemiologic scenario then, the hazard ratio from observational studies with such interval-censored sampling would result in underestimation of the true risk.

The LSVF study is consistent with other longitudinal studies of vaginal microbiota and STI risk. In a longitudinal study of 657 female sex workers in Kenya followed monthly for a median of six months, Martin et al. reported that absence of vaginal lactobacilli on culture was associated with an increased risk of acquiring HIV-1 infection and gonorrhea. High Nugent score was associated with increased risk of both HIV-1 acquisition and Trichomonas infection (5). In a study of 670 women at Pittsburgh-area health care clinics, Cherpes et al. found high Nugent score was associated with a 2 -fold increased risk for HSV-2 seroconversion (6). In a study of 1,140 women recruited into the GYN Infections Follow-through (GIFT) Study in the US, clusters of BV-associated vaginal microbiota identified by bacteriologic cultures were associated with development of PID (11). In vitro data also reveal that Trichomonas grows better at elevated $\mathrm{pH}$ (106), such as occurs in a clinically defined BV state (2).

In contrast to the observational studies above, a randomized trial provides the methodology to intervene and alter the vaginal microbiota and observe whether the intervention reduces adverse sequelae. Schwebke et al. randomized 107 women with both high Nugent score and lack of report of vaginal discharge or odor ("asymptomatic") to metronidazole prophylaxis or observation alone (107). Over 12 months of follow-up, they found metronidazole treatment of women with high Nugent scores was associated with significantly fewer cases of incident Chlamydia trachomatis infection compared with observation alone (no antibiotic) $(P=0.02)$. A large randomized trial of home screening of BV to prevent acquisition of STIs is ongoing and seeks to determine whether restoring the vaginal microbiota to a stable, low $\mathrm{pH}$, high lactic acid and/or lactobacillus-dominated state may help prevent acquisition of STIs upon exposure (108).
Several studies have reported on the interaction between BVassociated microbiota and HIV shedding, indicating an increased risk for transmission of HIV by women with BV. Cu-Uvin et al. reported in 2001 that BV defined by Amsel clinical criteria was significantly associated with HIV-1 RNA expression in the female genital tract compared with HIV-positive women without BV (7). Similarly, Coleman et al. reported that women with diminished Lactobacillus (as defined by Gram stain) had 15.8-fold greater endocervical HIV-1 RNA load than women with normal Lactobacillus levels (14). In a study that quantified bacteria in cervicovaginal lavage (CVL) by PCR, G. vaginalis count, M. hominis count, Nugent score, and presence of another lower genital-tract infection were associated with increased CVL HIV RNA levels (13). Lactobacilli count was inversely associated with CVL HIV RNA level, at borderline significance $(P=0.07)$. Of note, and in contrast with other studies, the authors did not find an association between Amsel criteria and CVL HIV RNA level, which the authors attributed to Amsel criteria being a less sensitive measure of detecting alterations of the vaginal microbiota.

Only a few molecular studies and, to date, no longitudinal molecular studies have investigated the interaction between vaginal microbiota and STIs. Using 16S rRNA gene sequences obtained by pyrosequencing, Spear et al. recently showed that there was a trend $(P=0.07)$ toward higher microbial diversity in the vaginal secretions of $\mathrm{HIV}^{+} \mathrm{BV}^{+}$subjects versus $\mathrm{HIV}^{-} \mathrm{BV}^{+}$women (109). A cross-sectional study of 396 asymptomatic women in the US (30) revealed a higher prevalence of T. vaginalis using PCR targeting the 18S rRNA and $\beta$-tubulin genes among women who were found to have lowlactobacillus community state by $16 \mathrm{~S}$ rRNA gene analysis (110).

These molecular studies highlight the strong interaction between vaginal microbiota and acquisition of and response to STIs. While the details of how the vaginal ecosystem provides protection against STI is still an active area of research, the lack of lactic acid-producing bacteria in vaginal microbiota of women with $\mathrm{BV}$ in addition to the high $\mathrm{pH}$ and local cytokine production that accompany BV appear to be the major factors affecting STI risk $(74,111,112)$. Information obtained from future longitudinal molecular studies may form the basis for new intervention strategies to prevent STIs based on the protective features of the vaginal microbiome.

\section{Summary}

$\mathrm{BV}$ is no longer considered just a nuisance condition. It is now recognized that vaginal microbiota play a major role in women's reproductive health. There is a large body of evidence that BV, whether it is defined clinically by cultivation, microscopy, or molecular methods and whether it is asymptomatic or symptomatic, is an independent risk factor for severe reproductive tract and obstetric sequelae, including preterm delivery and low birth weight, development of PID (11), acquisition of STIs (3-6, 104), and acquisition and transmission of $\operatorname{HIV}(5,7,8)$. Refinement of the biomarkers used to measure the vaginal microbiome and a better understanding of vaginal community dynamics may lead to interventions aimed at shifting to, and maintaining, more protective microbial communities. Multidisciplinary expertise in such fields as bioinformatics, epidemiology, gynecology, immunology, infectious diseases, microbial ecology, and molecular biology is necessary to exploit the data that will be generated on the vaginal microbiome, to identify new clinical interventions, and to assess these interventions rigorously. 


\section{Acknowledgments}

The author thanks Jacques Ravel, Larry Forney, Richard Cone, and their research groups for productive discussions and collaborations over the past several years. The author is supported by grant K01-AI080974 from the NIH National Institute of Allergy and Infectious Diseases.
Address correspondence to: Rebecca M. Brotman, Department of Epidemiology and Public Health, Institute for Genome Sciences, University of Maryland School of Medicine, BioPark Building II, 801 West Baltimore Street, Room Number 633, Baltimore, Maryland 21201, USA. Phone: 410.706.6767; Fax: 410.706.1482; E-mail: rbrotman@som.umaryland.edu.
1. Hillier SL, Holmes KK, Marrazzo JM. Bacterial vaginosis. In: Holmes K, et al. Sexually Transmitted Diseases. New York New York, USA: McGraw-Hill, Health Professions Division; 2008:737-768.

2. Amsel R, Totten PA, Spiegel CA, Chen KC, Eschenbach D, Holmes KK. Nonspecific vaginitis. Diagnostic criteria and microbial and epidemiologic associations. Am J Med. 1983;74(1):14-22.

3. Wiesenfeld HC, Hillier SL, Krohn MA, Landers DV, Sweet RL. Bacterial vaginosis is a strong predictor of Neisseria gonorrhoeae and Chlamydia trachomatis infection. Clin Infect Dis. 2003;36(5):663-668.

4. Peters SE, et al. Behaviors associated with Neisseria gonorrhoeae and Chlamydia trachomatis: cervical infection among young women attending adolescent clinics. Clin Pediatr (Phila). 2000;39(3):173-177.

5. Martin HL, et al. Vaginal lactobacilli, microbial flora, and risk of human immunodeficiency virus type 1 and sexually transmitted disease acquisition. Infect Dis. 1999;180(6):1863-1868.

6. Cherpes TL, Meyn LA, Krohn MA, Lurie JG, Hillier SL. Association between acquisition of herpes simplex virus type 2 in women and bacterial vaginosis. Clin Infect Dis. 2003;37(3):319-325.

7. Cu-Uvin S, et al. Association between bacterial vaginosis and expression of human immunodeficiency virus type 1 RNA in the female genital tract. Clin Infect Dis. 2001;33(6):894-896.

8 . Taha TE, et al. Bacterial vaginosis and disturbances of vaginal flora: association with increased acquisition of HIV. AIDS. 1998;12(13):1699-1706.

9. Schwebke JR. Gynecologic consequences of bacterial vaginosis. Obstet Gynecol Clin North Am. 2003 30(4):685-694.

10. Atashili J, Poole C, Ndumbe PM, Adimora AA, Smith JS. Bacterial vaginosis and HIV acquisition: a meta-analysis of published studies. AIDS 2008;22(12):1493-1501.

11. Ness RB, et al. A cluster analysis of bacterial vaginosis-associated microflora and pelvic inflammatory disease. Am J Epidemiol. 2005;162(6):585-590.

12. Cohn JA, et al. HIV-inducing factor in cervicovaginal secretions is associated with bacterial vaginosis in HIV-1-infected women. I Acquir Immune Defic Syndr. 2005;39(3):340-346

13. Sha BE, et al. Female genital-tract HIV load correlates inversely with Lactobacillus species but positively with bacterial vaginosis and Mycoplasma hominis. J Infect Dis. 2005;191(1):25-32.

14. Coleman JS, et al. Infectious correlates of HIV-1 shedding in the female upper and lower genital tracts. AIDS. 2007;21(6):755-759.

15. Cherpes TL, Melan MA, Kant JA, Cosentino LA, Meyn LA, Hillier SL. Genital tract shedding of herpes simplex virus type 2 in women: effects of hormonal contraception, bacterial vaginosis, and vaginal group B Streptococcus colonization. Clin Infect Dis. 2005;40(10):1422-1428.

16. Oakeshott P, Hay P, Hay S, Steinke F, Rink E, Kerry $\mathrm{S}$. Association between bacterial vaginosis or chlamydial infection and miscarriage before 16 weeks' gestation: prospective community based cohort study. BMJ. 2002;325(7376):1334

17. Donders GG, Van Bulck B, Caudron J, Londers L, Vereecken A, Spitz B. Relationship of bacterial vaginosis and mycoplasmas to the risk of spontaneous abortion. Am J Obstet Gynecol. 2000;183(2):431-437.

18. Llahi-Camp JM, Rai R, Ison C, Regan L, TaylorRobinson D. Association of bacterial vaginosis with a history of second trimester miscarriage. Hum Reprod. 1996;11(7):1575-1578.

19. Nelson DB, Bellamy S, Nachamkin I, Ness RB, Macones GA, Allen-Taylor L. First trimester bacterial vaginosis, individual microorganism levels, and risk of second trimester pregnancy loss among urban women. Fertil Steril. 2007;88(5):1396-1403.

20. Nelson DB, et al. Preterm labor and bacterial vaginosis-associated bacteria among urban women. JPerinat Med. 2009;37(2):130-134

21. Hillier SL, et al. Association between bacterial vaginosis and preterm delivery of a low-birth-weight infant. The Vaginal Infections and Prematurity Study Group. NEngl J Med. 1995;333(26):1737-1742.

22. Meis PJ, et al. The preterm prediction study: significance of vaginal infections. National Institute of Child Health and Human Development MaternalFetal Medicine Units Network. Am J Obstet Gynecol. 1995;173(4):1231-1235

23. Nygren P, et al. Evidence on the benefits and harms of screening and treating pregnant women who are asymptomatic for bacterial vaginosis: an update review for the U.S. Preventive Services Task Force. Ann Intern Med. 2008;148(3):220-233.

24. Klebanoff MA, Schwebke JR, Zhang J, Nansel TR, Yu KF, Andrews WW. Vulvovaginal symptoms in women with bacterial vaginosis. Obstet Gynecol. 2004;104(2):267-272.

25. Hugenholtz P, Goebel BM, Pace NR. Impact of culture-independent studies on the emerging phylogenetic view of bacterial diversity. J Bacteriol. 1998;180(18):4765-4774

26. Ronaghi M. Pyrosequencing sheds light on DNA sequencing. Genome Res. 2001;11(1):3-11.

27. Margulies M, et al. Genome sequencing in microfabricated high-density picolitre reactors. Nature. 2005;437(7057):376-380.

28. Fredricks DN, Fiedler TL, Marrazzo JM. Molecular identification of bacteria associated with bacterial vaginosis. NEngl J Med. 2005;353(18):1899-1911.

29. Ferris MJ, Masztal A, Aldridge KE, Fortenberry JD, FidelPL Jr, Martin DH. Association of Atopobium vaginae, a recently described metronidazole resistant anaerobe, with bacterial vaginosis. BMC Infect Dis. 2004;4:5

30. Ravel J, et al. Vaginal microbiome of reproductive-age women. Proc Natl Acad Sci U S A. 2011; 108 suppl 1:4680-4687

31. Sobel JD, et al. Suppressive antibacterial therapy with $0.75 \%$ metronidazole vaginal gel to prevent recurrent bacterial vaginosis. Am J Obstet Gynecol. 2006;194(5):1283-1289.

32. Bradshaw CS, et al. High recurrence rates of bacterial vaginosis over the course of 12 months after oral metronidazole therapy and factors associated with recurrence. J Infect Dis. 2006;193(11):1478-1486.

33. Swidsinski A, et al. An adherent Gardnerella vaginalis biofilm persists on the vaginal epithelium after standard therapy with oral metronidazole. Am J Obstet Gynecol. 2008;198(1):97-6.

34. Workowski KA, Berman S, Centers for Disease Control and Prevention (CDC). Sexually transmitted diseases treatment guidelines, 2010. MMWR Recomm Rep. 2010;59(RR-12):1-110.

35. Spiegel CA, Amsel R, Holmes KK. Diagnosis of bacterial vaginosis by direct gram stain of vaginal fluid. J Clin Microbiol. 1983;18(1):170-177.

36. Ison CA, Hay PE. Validation of a simplified grading of Gram stained vaginal smears for use in genitourinary medicine clinics. Sex Transm Infect. 2002;78(6):413-415.

37. Nugent RP, Krohn MA, Hillier SL. Reliability of diagnosing bacterial vaginosis is improved by a standardized method of gram stain interpretation. J Clin Microbiol. 1991;29(2):297-301.

38. Joesoef MR, Hillier SL, Josodiwondo S, Linnan M. Reproducibility of a scoring system for gram stain diagnosis of bacterial vaginosis. JClin Microbiol. 1991; 29(8):1730-1731.

39. Schwebke JR, Hillier SL, Sobel JD, McGregor JA, Sweet RL. Validity of the vaginal gram stain for the diagnosis of bacterial vaginosis. Obstet Gynecol. 1996;88(4 pt 1):573-576.

40. Koumans EH, et al. The prevalence of bacterial vaginosis in the United States, 2001-2004; associations with symptoms, sexual behaviors, and reproductive health. Sex Transm Dis. 2007;34(11):864-869.

41. Morgan DJ, Aboud CJ, McCaffrey IM, Bhide SA, Lamont RF, Taylor-Robinson D. Comparison of Gram-stained smears prepared from blind vaginal swabs with those obtained at speculum examination for the assessment of vaginal flora. Br J Obstet Gynaecol. 1996;103(11):1105-1108

42. Brotman RM, Ghanem KG, Klebanoff MA, Taha TE, Scharfstein DO, Zenilman JM. The effect of vaginal douching cessation on bacterial vaginosis: a pilot study. Am J Obstet Gynecol. 2008;198(6):628-7.

43. Schwebke JR, Morgan SC, Weiss HL. The use of sequential self-obtained vaginal smears for detecting changes in the vaginal flora. Sex Transm Dis. 1997; 24(4):236-239.

44. Brotman RM, Erbelding EJ, Jamshidi RM, Klebanoff MA, Zenilman JM, Ghanem KG. Findings associated with recurrence of bacterial vaginosis among adolescents attending sexually transmitted diseases clinics. J Pediatr Adolesc Gynecol. 2007; 20(4):225-231.

45. Hallen A, Pahlson C, Forsum U. Bacterial vaginosis in women attending STD clinic: diagnostic criteria and prevalence of Mobiluncus spp. Genitourin Med. 1987;63(6):386-389.

46. Johnson HL, Ghanem KG, Zenilman JM, Erbelding EJ. Sexually transmitted infections and adverse pregnancy outcomes among women attending inner city public sexually transmitted diseases clinics. Sex Transm Dis. 2011;38(3):167-171.

47. Lamont RF, Morgan DJ, Wilden SD, Taylor-Robinson D. Prevalence of bacterial vaginosis in women attending one of three general practices for routine cervical cytology. Int J STD AIDS. 2000;11(8):495-498.

48. Morris M, Nicoll A, Simms I, Wilson J, Catchpole M. Bacterial vaginosis: a public health review. BJOG. 2001;108(5):439-450.

49. Wawer MJ, et al. Control of sexually transmitted diseases for AIDS prevention in Uganda: a randomised community trial. Rakai Project Study Group. Lancet. 1999;353(9152):525-535.

50. Verhelst R, et al. Comparison between Gram stain and culture for the characterization of vaginal microflora: definition of a distinct grade that resembles grade I microflora and revised categorization of grade I microflora. BMC Microbiol. 2005;5:61.

51. Lopes Dos Santos SG, et al. Gardnerella vaginalis comprises three distinct genotypes of which only two produce sialidase. Am J Obstet Gynecol. 2011; 204(5):450.e1-e7.

52. Brotman RM, Ravel J. Ready or not: the molecular diagnosis of bacterial vaginosis. Clin Infect Dis. 
2008;47(1):44-46.

53. Berger BJ, Kolton S, Zenilman JM, Cummings MC, Feldman J, McCormack WM. Bacterial vaginosis in lesbians: a sexually transmitted disease. Clin Infect Dis. 1995;21(6):1402-1405

54. Marrazzo JM, Koutsky LA, Eschenbach DA, Agnew K, Stine K, Hillier SL. Characterization of vaginal flora and bacterial vaginosis in women who have sex with women. J Infect Dis. 2002;185(9):1307-1313.

55. Schwebke JR. Bacterial vaginosis: are we coming full circle? J Infect Dis. 2009;200(11):1633-1635.

56. Schwebke JR, Desmond R. Risk factors for bacterial vaginosis in women at high risk for sexually transmitted diseases. Sex Transm Dis. 2005;32(11):654-658.

57. Beigi RH, Wiesenfeld HC, Hillier SL, Straw T, Krohn MA. Factors associated with absence of H2O2-producing Lactobacillus among women with bacterial vaginosis. J Infect Dis. 2005;191(6):924-929.

58. Koumans EH, Markowitz LE, Berman SM, St Louis ME. A public health approach to adverse outcomes of pregnancy associated with bacterial vaginosis. Int J Gynaecol Obstet. 1999;67 suppl 1:S29-S33.

59. Ness RB, et al. Can known risk factors explain racial differences in the occurrence of bacterial vaginosis? J Natl Med Assoc. 2003;95(3):201-212.

60. Tchamouroff SE, Panja SK. The association between receptive cunnilingus and bacterial vaginosis. Sex Transm Infect. 2000;76(2):144-145.

61. Brotman RM, Ravel J, Cone RA, Zenilman JM. Rapid fluctuation of the vaginal microbiota measured by Gram stain analysis. Sex Transm Infect. 2010; 86(4):297-302.

62. Schmid GP. The epidemiology of bacterial vaginosis. Int J Gynaecol Obstet. 1999;67 suppl 1:S17-S20.

63. Schwebke JR, Richey CM, Weiss HL. Correlation of behaviors with microbiological changes in vaginal flora. J Infect Dis. 1999;180(5):1632-1636.

64. Vutyavanich T, Pongsuthirak P, Vannareumol P, Ruangsri RA, Luangsook P. A randomized doubleblind trial of tinidazole treatment of the sexual partners of females with bacterial vaginosis. Obstet Gynecol. 1993;82(4 pt 1):550-554.

65. Mengel MB, et al. The effectiveness of single-dose metronidazole therapy for patients and their partners with bacterial vaginosis. J Fam Pract. 1989; 28(2):163-171.

66. Colli E, Landoni M, Parazzini F. Treatment of male partners and recurrence of bacterial vaginosis: a randomised trial. Genitourin Med. 1997;73(4):267-270.

67. Swedberg J, Steiner JF, Deiss F, Steiner S, Driggers DA. Comparison of single-dose vs one-week course of metronidazole for symptomatic bacterial vaginosis. JAMA. 1985;254(8):1046-1049.

68. Doderlein A. Das Scheidensekret und seine Bedeutung fur Puerperalfieber (1892). Whitefish, Montana, USA: Kessinger Publishing, LLC; 2010.

69. Verhelst R, et al. Cloning of 16S rRNA genes amplified from normal and disturbed vaginal microflora suggests a strong association between Atopobium vaginae, Gardnerella vaginalis and bacterial vaginosis. BMC Microbiol. 2004;4:16.

70. Boskey ER, Telsch KM, Whaley KJ, Moench TR, Cone RA. Acid production by vaginal flora in vitro is consistent with the rate and extent of vaginal acidification. Infect Immun. 1999;67(10):5170-5175.

71. Klaenhammer TR. Bacteriocins of lactic acid bacteria. Biochimie. 1988;70(3):337-349

72. Ocana VS, Pesce De Ruiz Holgado AA, NaderMacias ME. Characterization of a bacteriocin-like substance produced by a vaginal Lactobacillus salivarius strain. Appl Environ Microbiol. 1999; 65(12):5631-5635.

73. ten Brink B, Minekus M, van der Vossen JM, Leer RJ, Huis in't Veld JH. Antimicrobial activity of lactobacilli: preliminary characterization and optimization of production of acidocin B, a novel bacteriocin produced by Lactobacillus acidophilus M46.
J Appl Bacteriol. 1994;77(2):140-148.

74. Yudin MH, Landers DV, Meyn L, Hillier SL. Clinical and cervical cytokine response to treatment with oral or vaginal metronidazole for bacterial vaginosis during pregnancy: a randomized trial. Obstet Gynecol. 2003;102(3):527-534.

75. Owen DH, Katz DF. A vaginal fluid simulant. Contraception. 1999;59(2):91-95.

76. O'Hanlon DE, Moench TR, Harrold S, Cone RA Microbicide production by vaginal lactobacilli: vaginal acidity $(\mathrm{pH})$ and lactic acid or more potent than previously reported. Poster presentation at: Microbicides Conference; February 24-28, 2008; New Delhi, India.

77. Lai SK, et al. Human immunodeficiency virus type 1 is trapped by acidic but not by neutralized human cervicovaginal mucus. JVirol. 2009;83(21):11196-11200.

78. O'Hanlon DE, Moench TR, Cone RA. In vaginal fluid, bacteria associated with bacterial vaginosis can be suppressed with lactic acid but not hydrogen peroxide. BMC Infect Dis. 2011;11:200.

79. O'Hanlon DE, Lanier BR, Moench TR, Cone RA. Cervicovaginal fluid and semen block the microbicidal activity of hydrogen peroxide produced by vaginal lactobacilli. BMC Infect Dis. 2010;10:120.

80. Sobel JD. Bacterial vaginosis. Annu Rev Med. 2000; 51:349-356.

81. Ferris MJ, Norori J, Zozaya-Hinchliffe M, Martin DH. Cultivation-independent analysis of changes in bacterial vaginosis flora following metronidazole treatment. J Clin Microbiol. 2007;45(3):1016-1018.

82. Ghanem KG, Hutton HE, Zenilman JM, Zimba R, Erbelding EJ. Audio computer assisted self interview and face to face interview modes in assessing response bias among STD clinic patients. Sex Transm Infect. 2005;81(5):421-425.

83. Forney LJ, Foster JA, Ledger W. The vaginal flora of healthy women is not always dominated by lactobacillus species. J Infect Dis. 2006;194(10):1468-1469.

84. Bartlett JG, et al. Quantitative bacteriology of the vaginal flora. J Infect Dis. 1977;136(2):271-277.

85. Hay PE, Ugwumadu A, Chowns J. Sex, thrush and bacterial vaginosis. Int J STD AIDS. 1997;8(10):603-608.

86. Keane FE, Ison CA, Taylor-Robinson D. A longitudinal study of the vaginal flora over a menstrual cycle. Int J STD AIDS. 1997;8(8):489-494.

87. Priestley CJ, Jones BM, Dhar J, Goodwin L. What is normal vaginal flora? Genitourin Med. 1997; 73(1):23-28.

88. Verstraelen H, Verhelst R, Claeys G, De Backer E, Temmerman M, Vaneechoutte M. Longitudinal analysis of the vaginal microflora in pregnancy suggests that L. crispatus promotes the stability of the normal vaginal microflora and that $\mathrm{L}$. gasseri and/or L. iners are more conducive to the occurrence of abnormal vaginal microflora. BMC Microbiol. 2009;9:116.

89. Srinivasan S, et al. Temporal variability of human vaginal bacteria and relationship with bacterial vaginosis. PLoS ONE. 2010;5(4):e10197.

90. McCook A. The vagina catalogues. Nat Med. 2011; 17(7):765-767.

91. Peterson J, et al. The NIH human microbiome project. Genome Res. 2009;19(12):2317-2323.

92. Eschenbach DA, et al. Influence of the normal menstrual cycle on vaginal tissue, discharge, and microflora. Clin Infect Dis. 2000;30(6):901-907.

93. Brotman RM, et al. A longitudinal study of vaginal douching and bacterial vaginosis--a marginal structural modeling analysis. Am J Epidemiol. 2008; 168(2):188-196.

94. Neggers YH, et al. Dietary intake of selected nutrients affects bacterial vaginosis in women. J Nutr. 2007 137(9):2128-2133.

95. Mercer BM, Taylor MC, Fricke JL, Baselski VS, Sibai BM. The accuracy and patient preference for self-collected group B Streptococcus cultures. Am J
Obstet Gynecol. 1995;173(4):1325-1328

96. Kim TK, et al. Heterogeneity of vaginal microbial communities within individuals. J Clin Microbiol. 2009;47(4):1181-1189.

97. Nelson DB, Bellamy S, Gray TS, Nachamkin I. Selfcollected versus provider-collected vaginal swabs for the diagnosis of bacterial vaginosis: an assessment of validity and reliability. J Clin Epidemiol. 2003;56(9):862-866.

98. Forney LJ, et al. Comparison of self-collected and physician-collected vaginal swabs for microbiome analysis. J Clin Microbiol. 2010;48(5):1741-1748.

99. Menard JP, Fenollar F, Raoult D, Boubli L, Bretelle F. Self-collected vaginal swabs for the quantitative real-time polymerase chain reaction assay of Atopobium vaginae and Gardnerella vaginalis and the diagnosis of bacterial vaginosis [published online ahead of print July 26, 2011]. Eur J Clin Microbiol Infect Dis. doi:10.1007/s10096-011-1341-8.

100. Wasserheit JN. Epidemiological synergy. Interrelationships between human immunodeficiency virus infection and other sexually transmitted diseases. Sex Transm Dis. 1992;19(2):61-77.

101. Grosskurth $\mathrm{H}$, et al. Impact of improved treatment of sexually transmitted diseases on HIV infection in rural Tanzania: randomised controlled trial. Lancet. 1995;346(8974):530-536.

102.Laga M, et al. Non-ulcerative sexually transmitted diseases as risk factors for HIV-1 transmission in women: results from a cohort study. AIDS. 1993; 7(1):95-102.

103. Peipert JF, Lapane KL, Allsworth JE, Redding CA, Blume JD, Stein MD. Bacterial vaginosis, race, and sexually transmitted infections: does race modify the association? Sex Transm Dis. 2008;35(4):363-367.

104.Brotman RM, et al. Bacterial vaginosis assessed by gram stain and diminished colonization resistance to incident gonococcal, chlamydial, and trichomonal genital infection. J Infect Dis. 2010; 202(12):1907-1915

105.Ness RB, Kip KE, Soper DE, Stamm CA, Rice P, Richter HE. Variability of bacterial vaginosis over 6- to 12-month intervals. Sex Transm Dis. 2006; 33(6):381-385.

106.McGrory T, Meysick K, Lemchuk-Favel LT, Garber GE. The interaction of Lactobacillus acidophilus and Trichomonas vaginalis in vitro. J Parasitol. 1994; 80(1):50-54.

107. Schwebke JR, Desmond R. A randomized trial of metronidazole in asymptomatic bacterial vaginosis to prevent the acquisition of sexually transmitted diseases. Am J Obstet Gynecol. 2007;196(6):517.

108. National Institute of Allergy and Infectious Diseases (NIAID). Bacterial vaginosis home screening to prevent STDs. NIH web site. http://clinicaltrials.gov/ct2/show/NCT00667368. Accessed September 19, 2011.

109.Spear GT, Sikaroodi M, Zariffard MR, Landay AL, French AL, Gillevet PM. Comparison of the diversity of the vaginal microbiota in HIV-infected and HIV-uninfected women with or without bacterial vaginosis. J Infect Dis. 2008;198(8):1131-1140.

110. Brotman RM, et al. 2011. Association between Trichomonas vaginalis and the vaginal microbiota among asymptomatic reproductive-age women in the United States: A cross-sectional study. Paper presented at: 19th Biennial Congress of the International Society for Sexually Transmitted Disease Research; July 11-13, 2011; Quebec City, Quebec, Canada.

111.Hillier SL. The vaginal microbial ecosystem and resistance to HIV. AIDS Res Hum Retroviruses. 1998; 14 suppl 1:S17-S21.

112.Redondo-Lopez V, Cook RL, Sobel JD. Emerging role of lactobacilli in the control and maintenance of the vaginal bacterial microflora. Rev Infect Dis. 1990;12(5):856-872. 